\title{
Formas de sociabilidad y movilidad profesional en los altos niveles ejecutivos: los headhunters y el manejo del mercado de trabajo directivo
}

\author{
Florencia Luci \\ Universidad de Buenos Aires. Instituto de Investigaciones Gino Germani \\ florluci@gmail.com
}

Recibido: 23-06-2011

Aceptado: 12-09-2011

\section{Resumen}

Este artículo analiza la práctica profesional de las consultoras que se dedican a la búsqueda y la recolocación laboral de los ejecutivos de empresas: los headhunters. El objetivo es mostrar que, además de simples agencias de empleo, estos expertos cumplen un rol central en la constitución del mercado de trabajo directivo de dos maneras. Por un lado, puesto que se trata de agentes altamente implicados en la construcción de redes socioprofesionales, intervienen en la acumulación de capital social y en la configuración de formas de prestigio y opinión que afectan a la movilidad profesional de los mánagers. Por otra parte, influyen en los términos en que se organiza la oferta y la demanda de ejecutivos: no sólo afectan a este mercado en su rol de agentes activos del reclutamiento de los directivos, sino que pueden, también, influir en las condiciones de contratación y de acuerdo salarial. En suma, el caso de los headhunters muestra cómo la construcción de relaciones sociales en mercados contribuye a forjar redes, opinión y valoración sobre las personas organizando diferentes oportunidades de carrera.

Palabras clave: cazadores de talento; intermediarios; mánagers; gran empresa; empresas consultoras; carrera profesional.

Abstract. Forms of sociability and professional recruitment in top management levels: Headhunters' making of the executive job market

This article analyzes the professional practice of executive search consultants dedicated to the recruitment of high profile managers: headhunters. The aim is to show that, more than simple placement agencies, headhunters accomplish a central role in shaping the executive job market in two ways. On the one hand, since they are highly involved in the creation of socio-professional networks, headhunters facilitate the accumulation of social capital, prestige and opinion that affect managers' recruitment. On the other hand, they take part in organizing the executive job market by not only controlling the hiring of managers, but also by having an effect on employment conditions and wage adjustment. To sum up, 
the study of headhunters' professional practice shows that social relationships in markets contribute to building networks, opinions, and assessments of people by organizing different career opportunities.

Keywords: executive search consultancy; intermediary; managers; large companies; job market; professional career.

\section{Sumario}

1. Introducción 6. La construcción de la opinión:

2. Objetivos y metodología

3. La circulación y la recolocación de los directivos: un mercado en manos de headhunters

4. Las búsquedas de alto nivel: una cuestión discreta el mundo de las referencias

7. Las formas de la transacción, la intervención y la construcción del mercado del management

8. Conclusiones

Referencias bibliográficas

5. El trabajo de los «cazadores de talentos» y las ventajas de figurar en la base

\section{Introducción}

Headhunter — literalmente, 'cazador de cabezas' - es la expresión en inglés para referirse a las consultoras que se dedican a la búsqueda laboral y el reclutamiento de ejecutivos de alto nivel. Por cierto, una buena porción del mercado laboral de los mánagers — es decir, el conjunto de relaciones de compra y venta de fuerza de trabajo directiva - queda en manos de estos «cazadores de talentos».

En esencia, el trabajo de los headhunters consiste en encontrar candidatos para los puestos que requieren las firmas que los contratan. Su habilidad reside en asegurar el enlace entre su cliente - la empresa- y el futuro ejecutivo contratado: sus servicios son pagados una vez que el candidato seleccionado acepta la oferta de trabajo e ingresa en la empresa ${ }^{1}$. Siguiendo la terminología de Burt (1995), unen los «agujeros estructurales» entre dos partes que de otro modo habrían permanecido sin conexión. Ahora bien, como señalan Finlay y Coverdill (2000), su posición estratégica uniendo una red de relaciones no alcanza para explicar la tarea que estos agentes desempeñan: las características que asume la relación de intercambio son asimismo importantes para comprender esta singular profesión y el tipo de intervención que sus agentes realizan en la constitución del mercado laboral de los directivos de empresas.

1. A este respecto, Finlay y Coverdill (2000) señalan el alto nivel de competencia que existe entre los headhunters: dado que se trata de un mercado sin regulaciones específicas y cuyo modo de pago se efectiviza tras la contratación del candidato propuesto, basta que otro headhunter ofrezca un candidato más conveniente para que la operación se cierre en su favor. El trabajo realizado por el primer headhunter que intervino en esa búsqueda queda sin compensación económica. 
Según explica Bessy (1997), el análisis de la función que desempeñan los «intermediarios» privados ofrece un punto de observación interesante sobre la relación entre las empresas y el mercado de trabajo. Dicho análisis no solamente informa sobre las competencias laborales que se valoran y las formas de selección que prevalecen en un espacio determinado, sino que, además, permite examinar el modo en que se afecta el «equilibrio» del mercado de trabajo. Como sostiene este autor, no se trata de simples intermediarios que funcionan como un puente entre una persona y una empresa, sino de agentes que intervienen activamente en la configuración del mercado de trabajo.

\section{Objetivos y metodología}

Este artículo se propone reflexionar sobre la práctica profesional de las consultoras que se dedican a la "caza de talento» ejecutivo. El objetivo es exponer la hipótesis que sugiere que, al mismo tiempo que agencias de empleo, estos agentes cumplen un rol central en la constitución del mercado de trabajo directivo de dos maneras. En primer lugar, dado que están altamente implicados en la construcción de redes socioprofesionales, intervienen en la acumulación de capital social, así como en la configuración de redes de prestigio y opinión que afectan a las oportunidades laborales de los mánagers. Como se verá, la estrategia de los headhunters incluye un complejo mundo de relaciones en el cual la reputación, la discreción y las redes sociales son centrales. En segundo lugar, participan en la construcción de los términos en que se organiza la oferta y la demanda de directivos: no sólo afectan al mercado ejecutivo en su rol de agentes activos de la circulación y la recolocación de los directivos, sino que pueden influir en las condiciones de contratación y de acuerdo salarial. En suma, el caso de los headhunters muestra cómo la construcción de relaciones sociales en mercados (Fligstein y Dauter, 2007) contribuye a construir mejores oportunidades de carrera, así como a forjar la opinión y la valoración sobre las personas.

La metodología ${ }^{2}$ que sustenta este artículo incluye un trabajo de investigación cualitativa realizado en ocho grandes empresas ${ }^{3}$ de Argentina, escogidas en base al ranking de las cien firmas con mayor volumen de facturación que anualmente produce la revista $M e r c a d o^{4}$. A fin de contar con un panorama variado de los tipos de empresas que componen la cúpula empresaria argentina (Azpiazu y Basualdo, 2009), se seleccionaron firmas de diversos sectores -industriales, servicios, consultoría, construcción-y formas de propiedad

2. El trabajo de campo fue realizado gracias al financiamiento otorgado por el Consejo Nacional de Investigaciones Científicas y Técnicas (CONICET) para la realización de mi tesis doctoral (Luci, 2010a).

3. Defino "grandes empresas» según la Encuesta Nacional a Grandes Empresas (ENGE), realizada por el Instituto Nacional de Estadística y Censos (INDEC), que recaba datos referidos a las quinientas empresas privadas más grandes del país, disponible en: www.indec.gov.ar.

4. Puesto que las estadísticas oficiales no revelan el nombre de las compañías, el ranking de las mayores firmas de Argentina que produce la revista Mercado es el método habitualmente utilizado por los especialistas en estudios corporativos (Azpiazu y Basualdo, 2009). 
- firmas multinacionales, grupos locales, empresas privatizadas. Esto no pretendió obtener algún tipo de representatividad, sino más bien conseguir una cierta diversidad que permitiera ver matices y que no sesgara los resultados por alguno de estos mismos elementos (tipo de industria, composición de capital, etc.), de igual modo que incluyera los tipos más significativos de empresas. Así, se escogió una firma automotriz, una constructora, una manufactura de productos de consumo masivo, una empresa de servicios financieros, una firma de auditoría a empresas, una cadena de supermercados y dos empresas privatizadas - de telefonía y electricidad. Los orígenes del capital incluyen procedencias norteamericana, alemana, inglesa, suiza, francesa, española, italiana y argentina.

En estas ocho empresas, fueron entrevistados 88 mánagers (68 hombres y 20 mujeres) de distintos departamentos y niveles jerárquicos, entre octubre de 2007 y junio de 2008. Se buscó representar el porcentaje de hombres y mujeres que poseen las estructuras jerárquicas: si bien esto varía según las empresas, aproximadamente un $80 \%$ son varones y un $20 \%$, mujeres (Luci, 2010b). El mismo criterio fue seguido para la repartición por nivel jerárquico: directores y gerentes. Si bien depende del tamaño de las empresas, la estructura gerencial cuenta entre 25 y 45 personas y tiene en su interior uno o dos subniveles jerárquicos. Por el contrario, sólo entre 5 y 12 personas conforman el directorio. En total, fueron entrevistados de 3 a 4 directores por firma y de 7 a 8 gerentes y jefes de cada empresa.

Se realizaron, también, 12 entrevistas en profundidad a los directores y responsables de recursos humanos, así como a informantes clave de diversos ámbitos del mundo de los negocios (consultores, headhunters, editores, dirigentes de asociaciones empresariales, de escuelas de negocios). Asimismo, se utilizó material documental interno de las firmas y se realizó un trabajo de observación etnográfica en las presentaciones de los programas de MBA - Master in Business Administration - que cuatro business schools (dos españolas, una norteamericana y una argentina) realizaron en Buenos Aires en 2007 (Luci, 2009).

\section{La circulación y la recolocación de los directivos: un mercado en manos de headhunters}

Las consultoras que se dedican a la búsqueda ejecutiva funcionan en la Argentina desde mediados de los años sesenta, poco tiempo después de su surgimiento en los Estados Unidos (Neffa y Korinfeld, 2006). Aunque en ese momento las firmas que se instalaron en el país no eran más que unas pocas sucursales de las principales consultoras globales, las décadas siguientes vieron incrementar considerablemente su número y, sobre todo, la ampliación de la oferta de sus servicios. En su mayoría, están registradas jurídicamente como empresas unipersonales o sociedades de hecho. También, en algunos casos, se registran como sociedad anónima o de responsabilidad limitada. Estos agentes no tienen ningún tipo de control o regulación estatal para su funcionamiento.

Las empresas consideradas en esta investigación utilizan, para sus búsquedas ejecutivas, los servicios expertos que brindan las grandes multinacionales de headhunting. Los datos recabados permiten, en efecto, comprobar que son las 
principales consultoras del mundo - y no las asesoras locales - las que dominan el mercado ejecutivo argentino. Al igual que sucede con las consultoras en temas generales de management, el empleo de multinacionales del headhunting responde a diversos factores: a los contratos internacionales que las firmas más globales acuerdan para toda la corporación, a la necesidad de legitimar el resultado de una búsqueda en el reporte a la casa matriz o bien a la confianza que inspira acudir a los principales expertos del mundo.

Casi todas son consultoras multinacionales que tienen una franquicia o un representante en la Argentina. Nosotros trabajamos con ese tipo de headhunters y no con empresas locales, porque, sobre todo, si son posiciones de directores, reportamos el estatus a Estados Unidos. Entonces, que sea una consultora americana o mundial, le da más jerarquía. (Gerenta, 35 años, casada, 1 hijo)

La mayoría de las empresas que integran esta investigación se proponen desarrollar a sus mánagers internamente, es decir, reclutan a jóvenes profesionales que van formando de acuerdo con las pautas de socialización propias. Esto supone contar con futuros directivos que no solamente conocen en profundidad la "cultura» y el funcionamiento de la empresa, sino que, sobre todo, es más probable que desarrollen un sentido de compromiso y lealtad hacia la firma. Por este motivo, un alto porcentaje de los directivos entrevistados ha realizado gran parte de su carrera en el seno de la empresa, y no «saltando» por diversas compañías (Defillippi y Arthur, 1994).

Ahora bien, si ciertamente los responsables de recursos humanos enfatizan que sus directivos provienen del reclutamiento interno — son cuadros de la firma-, reconocen, no obstante, que alrededor de un $10 \%$ de las posiciones directivas para las cuales no existe un candidato interno se reclutan «del mercado». Este porcentaje coincide, asimismo, con los datos recabados en mi trabajo de campo: un 9,6\% de los entrevistados obtuvo su puesto actual a través de un headhunter, lo cual supone el ingreso inmediato a un puesto directivo.

Por otra parte, aunque el porcentaje del mercado de trabajo ejecutivo que efectivamente concretan los cazadores de talentos ronde el $10 \%$, hay que resaltar que un $72,6 \%$ de los entrevistados ha sido contactado por alguno de estos agentes. Es decir que los headhunters tienen un altísimo nivel de contacto con los mánagers que ocupan las posiciones directivas de las principales firmas del país. En virtud de esto, se convierten, como se verá, en agentes centrales del mercado de trabajo directivo.

\section{Las búsquedas de alto nivel: una cuestión discreta}

¿Por qué las empresas se desligan de la tarea de buscar a sus propios ejecutivos y la depositan en manos de $\operatorname{costosos}^{5}$ servicios expertos? ¿Por qué no realizar el

5. La remuneración de los headhunters es de aproximadamente un tercio de la remuneración anual del ejecutivo contratado. 
reclutamiento de los directivos a través de su propio departamento de recursos humanos o la publicación de anuncios en los periódicos? Finlay y Coverdill (2000) exponen dos razones que explican esto para el caso americano y que son igualmente útiles para explicar el caso francés (Gautié, Godechot y Sorignet, 2005), así como también, según pude comprobar, el argentino. Por un lado, puesto que las empresas se proponen formar cuadros propios, la tercerización de este servicio es una forma de solucionar una función para la cual las firmas tienen un know-how poco desarrollado. En este sentido, los headhunters ofrecen un servicio rápido y eficiente para una actividad que las empresas no llevan adelante tan frecuentemente. Por otro lado, el recurso a un reclutador externo permite sortear las disputas políticas internas que un reclutamiento de alto nivel conlleva y asegurar una selección más «objetiva».

Ahora bien, además de una cuestión de know-how y de política interna, mi trabajo de campo me lleva a postular que recurrir a estos expertos tiene además como objetivo mantener la discreción en torno de una búsqueda que se vería publicitada si se recurriera a medios de comunicación de masas. Por el contrario, el trabajo con base en sus propias redes de relaciones permite a los headhunters tratar con reserva una cuestión que es central para las firmas: el reemplazo de uno de sus ejecutivos clave tiene, ciertamente, una gran relevancia, tanto para los accionistas como para el resto de los mánagers, de igual modo que es una cuestión que «interesa» al mercado del management ${ }^{6}$.

$\mathrm{Al}$ respecto, vale introducir una cuestión que resultó nodal en la indagación acerca de la relación entre mánagers y headhunters: la discreción y el secretismo que rodeó al tema. Si, a lo largo de toda la entrevista, los mánagers se mostraron abiertos y dispuestos a hablar de las diferentes dimensiones de su carrera y su profesión, las preguntas acerca de su vínculo con empresas de caza de talentos estuvieron rodeadas, al menos inicialmente, por un halo de sospecha. En más de una ocasión, las respuestas a mis preguntas concluían con un tajante «Discúlpame, pero de esto no te puedo hablar» $\mathrm{O}$ «¿Para qué quieres saber esto?». Alertada luego de algunos intentos fallidos, hube de cambiar mi forma de indagación sobre el tema, e incluso banalizar la cuestión, a fin de romper el manto de reserva que lleva adherido. Me preguntaba, sin llegar a entender del todo bien, el porqué de una tal cautela. Como luego comprendería, la prudencia con que los mánagers tratan el tema o incluso se niegan a hablar de él expresa, casi como por carácter transitivo, la confidencialidad que rodea a la "caza» de ejecutivos y las relaciones que se entablan en torno de ella.

Efectivamente, tal como señalan mánagers, headhunters y directores de recursos humanos: las búsquedas de ejecutivos de alto nivel —altas gerencias y directores — no suelen realizarse a través de medios que impliquen visibilidad.

6. Al respecto, vale observar que lo que se denomina «pases» de ejecutivos — nombre que emula los "pases» del mundo deportivo y, sobre todo, futbolístico- figura en la sección de management y negocios de los principales periódicos. El trabajo documental desarrollado permite observar que tanto los cambios de empresas como las desvinculaciones de los principales mánagers son publicadas en estos medios. 
Publicar un aviso clasificado en el diario, por ejemplo, resulta impensable. El mercado laboral de los altos directivos se maneja con la más absoluta reserva: su tamaño reducido y la alta conexión que predomina hace que las personas se conozcan. Como explica un entrevistado que consiguió su actual puesto directivo a través de un pase logrado por un headhunter:

[...] estas cosas las manejo con mucho cuidado, porque la gente se conoce. Ya a cierto nivel, no puedes mandar un currículum..., empapelar la ciudad. (Director, 42 años, casado, 4 hijos)

En el mismo sentido, un director de recursos humanos sostiene que raramente un mánager responda a un aviso clasificado: las búsquedas de "gerente para arriba» se manejan a través de expertos.

Si tu me dices: «Tengo que buscar de un gerente para arriba», yo lo manejo con un headhunter, porque si pones un aviso, no te vienen, o te viene el que no está conforme, está desmotivado o no es bueno. Seguramente, el que es un excelente ejecutivo, si todo funciona bien, está muy bien cuidado por su empresa, está muy bien mimado y raramente responda a un aviso. Hay que ir y sacarlo; primero encontrarlo, identificar quién es y después llamarlo y decirle: «Está esta posibilidad. ¿'Te interesa?». (Director, 41 años, casado, 2 hijos)

No solamente publicar un aviso de búsqueda de un mánager de alto nivel es una práctica inhabitual, sino que se presupone que el ejecutivo que responde a un aviso clasificado es aquel que está desmotivado o que no es bueno en su trabajo. El sentido común compartido entre los agentes de este espacio entiende que un «excelente ejecutivo» está cuidado por su empresa — «está muy bien mimado»-y difícilmente responda a un aviso. Más bien, la práctica habitual consiste en encontrar a esa persona — al buen mánager motivado- $\mathrm{y}$ «sacarlo»: huntearlo, cazarlo, ofreciéndole una propuesta laboral superadora.

Del mismo modo, un gerente entrevistado considera que, una vez alcanzado cierto nivel jerárquico, responder a un aviso del diario "ya no va». Es más, considera una "payasada» que una firma importante postule un puesto clave mediante la difusión masiva: él no respondería a una propuesta que surgiera de este modo. Lo más razonable, explica, es que la empresa realice una definición precisa del mánager que necesita junto con expertos y que salga a buscarlo.

A cierto nivel gerencial, responder a un aviso del diario, de Internet o lo que fuera ya no va. Yo, si veo publicaciones para $\mathrm{CFO}^{7}$ o para gerente general en el diario, no lo mando, son unos payasos. ¿Cómo lo vas a poner en el diario? Me parece ridículo. O sea, de los máximos responsables de tu empresa más vale que hayas diagramado el perfil, qué es lo que quieres, qué es lo que necesitas y sal a buscarlo. Sí, me parece más razonable que haya tipos que estén estudiando el perfil de los ejecutivos, su potencial, qué les interesa, qué es lo que les gusta,

7. Chief financial officer, o director de finanzas. 
dónde encajaría y que ellos manejen su cartera de posibilidades. (Gerente, 37 años, casado, 3 hijos)

Es allí donde el trabajo de expertos en caza de talentos resulta de interés tanto para los ejecutivos como para las empresas: su función de intervención en el mercado laboral supone el conocimiento de dicho mercado y el manejo de la «cartera de posibilidades» de los ejecutivos de acuerdo con las necesidades de las firmas. Como consecuencia de la función de intermediación que estos agentes realizan, a los mánagers les resulta vital tener contacto — «figurar en la base»- de un headhunter de cierta envergadura: puesto que, una vez alcanzado el rol gerencial, el mercado directivo se maneja principalmente a través de estos agentes, las posibilidades futuras de movimiento profesional están en buena medida condicionadas por las redes socioprofesionales que ellos organizan.

Ahora bien, los mánagers entrevistados diferencian muy precisamente a quiénes llaman headhunters de las consultoras que se dedican a las búsquedas de puestos ejecutivos de rango medio. Mientras que el término headhunter se reserva a las grandes firmas multinacionales que abarcan las búsquedas ejecutivas de alto rango en todo el mundo, las agencias que se encargan del mercado que abarca a las gerencias junior y jefaturas de área se denominan simplemente «consultoras». Como me explica un gerente:

Yo headhunters los llamo a los grandes. Los ocho que te mueven el mercado grande. El resto son consultoras de menor nivel. (Gerente, 36 años, casado, 1 hijo)

Esta diferenciación no es meramente nominativa, sino que supone la estipulación de un principio de distinción que contrapone a quienes tratan con headhunters de quienes tratan con consultoras. Tener trato directo con un headhunter, tener cierta relación de confianza con alguno de estos agentes, es, además de un capital que puede intervenir favoreciendo oportunidades profesionales, un símbolo de estatus (Goffman, 1951).

Por estos dos motivos - estatus y beneficios laborales_, los mánagers tratan de entablar una relación con alguno de los headhunters más importantes del mercado. Como señala un director de recursos humanos:

[...] los ejecutivos más o menos inquietos enseguida se hacen amigos de un hunter. (Director, 41 años, casado, 2 hijos)

\section{El trabajo de los «cazadores de talentos» y las ventajas de figurar en la base}

En su rol de intermediación entre las empresas y los mánagers, los headhunters construyen una relación unilateral con ambos agentes: son ellos quienes manejan los términos del vínculo y los puntos de contacto. Es así que la naturaleza de esta relación no tiene un único ángulo de interpretación, sino que varía de acuerdo con el sentido - la direccionalidad - en que se entabla el vínculo entre los agentes que participan: empresa, mánager y headhunter. Un directivo 
de la firma constructora explica del siguiente modo la doble circulación de la relación que pasa por la órbita de estos expertos.

La metodología del headhunter es: si yo lo tomo como cliente, le digo: «Necesito cubrir un puesto de gerente de logística». Él toma el tema, se le hace una descripción de más o menos qué competencias y capacidades necesitas y a partir de ahí lo que hacen es: miran en el mercado dónde hay, ya en actividad, esos gerentes. Entonces se enteran de que en tal empresa hay un gerente de logística como el que necesitamos. Tratan de ver cómo llegar a esa persona y, cuando llegan, lo llaman por teléfono y le dicen: "Tenemos una oferta..., ¿le interesaría?». Y ahí empieza la entrevista. Eso es desde usuario. Y del otro lado te suena el teléfono y te dicen: «Hola, sí, te llamamos porque un profesional conocido tuyo nos dio tu nombre, somos de una agencia de búsqueda de personal para empresas y hay una empresa del sector que busca un gerente de logística». (Gerente, 56 años, casado, 1 hijo)

En lo que respecta a la demanda por parte de las empresas, la relación laboral comienza cuando una firma contacta con una consultora especializada en búsquedas ejecutivas para cubrir una posición directiva —una gerencia senior o una dirección - que ha quedado vacante. El primer contacto entre el cliente - la empresa - y el proveedor - el headhunter - consiste, entonces, en una primera entrevista donde los responsables de recursos humanos de la firma le detallan al consultor el tipo de puesto que se debe cubrir y el perfil del mánager indicado.

Eymard-Duvernay y Marchal (2000) han resaltado el componente interpretativo que rodea al trabajo conjunto de definición de las competencias que se produce en la interacción entre los responsables de la empresa y el reclutador experto. A este respecto, hay que aclarar que la naturaleza del trabajo de campo emprendido no permite captar mucho de la riqueza que se produce en esta situación de interacción: esto habría requerido un trabajo de observación etnográfica de las entrevistas por las cuales los headhunters tratan con mánagers. En este sentido, los términos prácticos en que se realizan las operaciones de traducción (Callon, 1998) que configuran las normas y los valores que guían la interacción no son captados. Sin embargo, el trabajo de entrevistas - tanto con mánagers como con headhunters - ha sido rico, en el sentido de captar las formas en que se produce la relación de reclutamiento, así como las opiniones y las valoraciones acerca de las formas en que esto se produce.

El headhunter debe realizar, entonces, un trabajo de traducción de las necesidades del cliente, a fin de comprender qué tipo de mánager se requiere, cuáles son las características del puesto en cuestión, qué competencias son valoradas por la organización y, principalmente, qué tipo de «cultura» impera allí.

Lo primero que tiene que hacer la consultora es entender qué es lo que tu necesitas y sobre todo entender la cultura de la empresa. Un profesional puede funcionar muy bien en una empresa y tal vez muy mal en otra, no porque sea un mal profesional, sino porque no logra adaptarse a la cultura. Lo que tiene 
que hacer la consultora es entender, primero, el negocio en el que estamos, la necesidad del puesto, entender por qué estamos buscando ese puesto (si es un puesto nuevo, si existía pero había una persona que no funcionaba y entender por qué no funcionó, para no repetir el mismo error), cuál es el contenido de la tarea y centralmente la cultura de la empresa. Si no entiendes eso, muchos candidatos que tienen un currículum excelente después terminan fallando. Incluso estas compañías te ofrecen una garantía que si, en determinado plazo, el candidato renuncia, te hacen una búsqueda de nuevo, gratis. (Director, 41 años, casado, 2 hijos)

Como ya se ha resaltado (Wright, 1994; Selim, 1999), la «cultura» constituye una dimensión de análisis central por parte de las empresas. En este caso, se presupone que la comprensión de la «cultura corporativa» es importante para lograr un match adecuado. Quizás por eso, los responsables de recursos humanos prefieren trabajar con uno o dos consultores, y no más, con quienes tienen trato desde hace tiempo. Como dice Bessy (1997), el trabajo de reclutamiento se facilita si el consultor mantiene relaciones durables con la empresa que contrata los servicios. Por eso, el conocimiento previo establecido con una consultora que ya ha realizado búsquedas es un capital importante que permite a la empresa asegurar el éxito de la búsqueda, y a la consultora, fidelizar a un cliente.

Una vez establecidos los criterios de la pesquisa, el headhunter se dedica a buscar a un ejecutivo que se corresponda con el perfil solicitado por la empresa. Lo ideal será «cazar» a un ejecutivo en funciones que se desempeñe con alto rendimiento en alguna firma de envergadura. Por eso, buena parte del trabajo de los cazadores de talentos consiste en tener una base actualizada de los ejecutivos que ocupan las posiciones preeminentes de las principales firmas del país. Con este fin, realizan un trabajo previo y constante de mantenimiento de su fuente de datos.

El gran valor es la base de datos, son expertos en tener la base de datos actualizada y saben que Fulano está haciendo tal cosa en tal empresa y que Mengano está trabajando en tal otra. Saben si está contento, si no está contento, todo. Lo que ellos te venden rápidamente es una base de datos de ejecutivos. (Director, 41 años, casado, 2 hijos)

Parte del trabajo de mantener una base de datos actualizada supone que los headhunters se contacten con ejecutivos simplemente para "conocerse». Esto implica la concertación de entrevistas cuyo fin no es la realización de una oferta de trabajo puntual, sino un encuentro informal para analizar el perfil del mánager en cuestión e ingresarlo en la base de la consultora. Este es el caso de un gerente de una firma de servicios financieros que fue contactado por un headhunter para conocerlo, determinar su perfil mediante un test específico y quedar en relación para futuras búsquedas.

— Me han llamado, sin haber dejado yo un currículum ni nada.

- ¿Y cómo obtuvieron tus datos? ¿Tienes idea? 
-No. No te dicen. Ni tampoco lo pregunté. Pero sí he ido a entrevistas para conocernos y saber un poco de qué se trata. Linda experiencia. Me hicieron tests. Realmente estuvo muy bien.

— ¿Qué tipo de tests?

-Uno orientado al perfil, además de las entrevistas. Es para sacar tu perfil, para ver qué habilidades tienes dominantes.

(Gerente, 35 años, casado, 2 hijos)

Ahora bien, ¿cómo obtienen los datos de los ejecutivos? ¿Cómo llegan los headhunters a contactarse con los mánagers de las diversas firmas? La mayoría de los entrevistados afirma desconocer el modo por el cual estos expertos obtuvieron sus datos.

- ¿Sabes cómo consiguieron tus datos?

-No, no te dicen, tampoco. O te dicen: «Este es nuestro trabajo».

(Gerenta, 38 años, divorciada, 1 hijo)

De dónde los sacan es una incógnita. No sabes de dónde los sacan. Te llaman y te dicen: «Tengo un puesto, me gustaría que escucharas». (Gerenta, 35 años, casada, 1 hijo)

En general, se asume que el contacto generado con uno de estos agentes proviene de cadenas de relación y recomendación, aunque mayormente no se sabe de parte de quién.

Las dos veces me dijeron: «Alguien me refirió a ti». ¡Lástima que no me dijeran quién era, porque me habría encantado agradecerle, es muy honroso que te postulen! (Directora, 42 años, soltera)

Los tipos llaman a gente que conocen para ofrecerles un puesto, la persona dice que no y ellos le dicen: «iMe puedes recomendar a alguien?». Entonces te nombra y así es como llegan a ti. (Gerente, 33 años, casado)

Aunque la recomendación es uno de los principales mecanismos por los cuales los headhunters contactan con nuevos ejecutivos que nutren su base, también, el hecho de ocupar un puesto de relevancia en una gran empresa constituye un dato de por sí. Son puestos con «nombre y apellido», como me explicaría un consultor entrevistado. Por eso, los mánagers que han alcanzado cierta jerarquía saben que el hecho de ser eventuales ocupantes de un alto cargo en una de las principales compañías del país los tiene en la mira de las consultoras.

Una vez que estás en la posición dos o tres en esta empresa, te llaman para ofrecerte trabajo. A todos nos llaman. (Gerente, 33 años, casado, 1 hijo)

Empresas como esta ya representan un dato. Si sales a buscar un gerente de ventas, el hecho de hoy estar acá ya me hace estar en un listado de alguien. (Gerente, 39 años, casado, 3 hijos) 
Otras veces, el contacto con headhunters se deriva de la participación en diversas arenas de la «industria del management». Cursar un MBA o un seminario de posgrado en una importante escuela de negocios, local o extranjera, supone - tal como puede verse en Luci (2009) - beneficiarse de la red de relaciones que estos agentes cultivan. En particular, permite estrechar lazos con las principales consultoras. Del mismo modo, la activa participación que muchos mánagers tienen en diversos eventos, congresos, charlas, los ubica en un lugar de visibilidad que les permite entablar relaciones: «En realidad, por el hecho de que participamos en eventos y demás, se sabe quién ocupa cada puesto. Además te los encuentras en muchas de estas cosas» (gerente, 33 años, casado, 1 hijo). Igualmente, pertenecer a las mismas instituciones de prestigio conlleva la posibilidad de relacionarse con muchos de los principales agentes de esta industria: «a algunos los conozco incluso del Club de Harvard» (director, 50 años, casado). Por otra parte, las relaciones laborales que las compañías entablan con las consultoras que les proveen diversos servicios llevan a los mánagers a entrar en relación con headhunters. Como señala un director de la cadena de supermercados: «mis coach, los coach que me pone la compañía, son headhunters. Así que tengo relación todos los meses con ellos» (director, 42 años, casado, 4 hijos).

\section{La construcción de la opinión: el mundo de las referencias}

Gran parte del trabajo de los headhunters consiste, entonces, en reunir una base de datos que contenga información detallada de quienes ocupan las posiciones superiores de las principales firmas del país. La construcción de la base supone conectarse con estos mánagers, a fin de indagar las características de las funciones que desempeñan y evaluar — mediante entrevistas y tests- su perfil socioprofesional.

Uno de los principales modos de obtener información acerca de estas personas es, sin duda, la «recomendación»: «en general, sucede que, por alguna circunstancia, convocan a alguien y ese alguien termina pasando información tuya» (directora, casada, 2 hijos). Ciertamente, es a través de referencias anónimas como los headhunters van cultivando la densa red de contactos e información que constituye su principal acervo. Como explica un directivo, una vez que el headhunter contacta con un ejecutivo a quien no logra "cazar", la pregunta de rigor es aquella que deriva en la recomendación de algún otro mánager susceptible de ocupar el puesto.

¿Qué hace el headhunter cuando ve que contigo no llega a nada? Te dice: «¿No tendrás algún conocido?». Y ahí normalmente la gente dice: «Sí». Y ellos te dicen: «Dime el nombre, nosotros no vamos a decir que lo llamamos de tu parte». Así ellos van armando su base de datos a partir de recomendaciones que son anónimas. (Gerente, 56 años, casado, 1 hijo)

Aunque se trata de referencias anónimas, muchas veces la información que involucra a referidos y referentes se termina conociendo. Tal como expresa el ejecutivo citado: 
En realidad, las referencias son anónimas, pero, por ejemplo, yo le di el nombre de un amigo y, al cabo de un tiempo, mi amigo me llama y me dice: «iSabes que me fui de tal trabajo y entré a trabajar en XXX?». Y le digo: «Sí, ya sé, porque yo di tu nombre». (Ríe.) «iAh! ¿Tú fuiste?».

Ciertamente, el campo laboral de los altos ejecutivos conforma un mercado reducido donde la gente se conoce.

En este sentido, la recomendación que solicita el headhunter no sólo tiene como fin la obtención de un «dato» necesario para su actividad de búsqueda, sino que se propone, además, construir opinión sobre las personas. Las referencias no sólo permiten acumular nuevos contactos, sino que permiten sobre todo construir juicios de valor. Voy a sostener que el reconocimiento social que involucra la constitución de estas redes de valoración es una dimensión central de la recolocación de los ejecutivos y constituye una referencia decisiva sobre sus cualidades profesionales. De este modo, las redes de estima y reputación intervienen en el progreso de la carrera.

Cierto, el engrosamiento de la base de los headhunters no responde únicamente a un criterio numérico: no se trata sólo de contar con una gran cantidad de ejecutivos previamente contactados, sino de asegurarse que sean mánagers de excelencia. Antes de presentar a los candidatos finales de una búsqueda a las empresas clientes, los headhunters deben certificar que los seleccionados son, en verdad, buenos ejecutivos. Para ello, además de contar con la información que proviene de sus propias entrevistas y tests, verifican la calidad del candidato a proponer consultando a otros mánagers de su confianza ${ }^{8}$.

Los entrevistados reconocen que la llamada de un "headhunter amigo" para pedir su opinión acerca de algún ejecutivo es una práctica habitual. Una joven gerenta que ingresó en su empresa a través de uno de estos expertos explica que, tras la operación que concluyó con su ingreso a la compañía, quedó en muy buenas relaciones con los consultores que intervinieron en su caso. Los buenos términos de la relación entablada suponen que «a veces me llaman de esa consultora para que les recomiende gente cuando están haciendo búsquedas o para saber qué pienso de tal o cual» (gerenta, 36 años, soltera).

Un gerente de una empresa automotriz, cuyo único contacto con un headhunter fue a través de una entrevista, relata con cierto enojo que, al finalizar dicho encuentro, los consultores le hicieron preguntas sobre varias personas que se desempeñaban en cargos similares al suyo en otras empresas. Quizás el desconocimiento de los modos de acción de estos agentes lo llevó a traducir como una falta de respeto lo que en realidad es una práctica usual.

Me han hecho preguntas sobre alguno que otro. A mí me cayó mal. Qué opinaba de tal, que era alguien que trabajaba en otra empresa. Si lo conocía

8. Como señalan Eymard-Duvernay y Marchal (1997), muchas veces, las entrevistas tienen el inconveniente de privilegiar las cualidades interaccionales de los candidatos en detrimento de sus competencias profesionales. En este sentido, el recurso a la referencia sirve a los fines de conocer si «en el terreno» el mánager ha obtenido buenos resultados. 
o no y qué opinaba. La verdad que no me cayó para nada bien. (Gerente, 40 años, casado, 3 hijos)

Quienes están más familiarizados con la metodología de estos agentes saben que los pedidos de opinión y recomendación constituyen una parte fundamental de su actividad profesional. Uno de los ejecutivos de la manufactura de productos de consumo masivo, que, según afirma, es contactado por consultores con mucha frecuencia, sabe que los procesos de referencia tienen por objeto etiquetar a las personas según rótulos que estiman sus competencias socioprofesionales.

Sobre todo si el hunter te mueve a otra compañía, de alguna manera, hay como una especie de código: «Mira, te tiro un par de nombres de personas que son de los buenos», entonces ya esa persona es considerada «buena». (Gerente, 33 años, casado, 1 hijo)

Como me explicó un headhunter entrevistado, el hecho de que un mánager tenido en buen concepto por la consultora opine positivamente sobre alguien constituye un dato más que califica a los posibles candidatos. Y puesto que, en vistas de construir una apreciación adecuada, los headhunters buscan obtener la mayor cantidad de opiniones posible sobre los candidatos que consideran presentar a las empresas, el hecho de obtener valoraciones positivas de varios mánagers otorga un mayor grado de certeza a la selección. Es lo que los nativos llaman las «referencias cruzadas»: la superposición de recomendaciones sobre una persona contribuye a construir la confianza sobre su idoneidad para un puesto.

Ahora bien, es interesante observar que el mánager que opina sobre un colega a petición de un headhunter es, al mismo tiempo que evaluador, evaluado por estos. En efecto, tal como explica un alto directivo entrevistado, en esa petición de recomendación el hunter evalúa no sólo al futuro candidato, sino también al ejecutivo que da la recomendación, es decir, evalúa la referencia que este brinda. Y puesto que no solamente le pide consejo a él, sino a otros altos dirigentes que conozcan a la persona, el hecho de que su opinión se aleje mucho de la media puede dejarlo mal parado: «Si yo digo que tal tipo es un lince y después resulta que es un papanatas, me termino quemando yo». Dar una referencia acerca de alguien no es solamente un modo de evaluar a ese alguien en cuestión, sino que implica, simétricamente, la apreciación del mánager que emite el juicio.

El mundo de opiniones que se construye de esta forma es característico del modo en que se tejen las relaciones entre los directivos de alto nivel y estos singulares agentes de la industria del management. Adentrarse en este mundo supuso desentrañar los códigos y las formas de conducta que rodean a cada una de las relaciones que se entrelazan en este espacio. Lejos de tratarse de vínculos anodinos, los modos de la interacción se desarrollan de acuerdo con una gramática particular que interviene no solamente ofreciendo los términos de las conductas adecuadas, sino, además, forjando las formas del juicio, la apreciación y la estima de las personas. 
El modo «correcto» de entrar en contacto con un headhunter es tan sólo otro ejemplo de la importancia que tienen las formas de socialización (Simmel, 1986 [1908]). Según pude saber, presentarse uno mismo, espontáneamente, es una práctica que los mánagers saben que no lleva a buen puerto. $\mathrm{Al}$ igual que sucede en los clubes sociales más prestigiosos, alguien conocido debe presentar a la persona. Formar parte de este entre-soi socioprofesional tiene, ciertamente, sus reglas. Como explica un directivo de la firma constructora:

No está bien visto que tú salgas, que tú mismo vayas a presentarte a un hunter. Te van a tomar, te van a decir: «Déjame el currículum» o lo que sea, pero nada más. (Gerente, 56 años, casado, 1 hijo)

Por el contrario, formar legítimamente parte de la red de un headhunter se deriva del hecho de poseer un puesto con «nombre y apellido» o de la recomendación de un tercero a quien el headhunter conoce y estima. Es por la vía de la intermediación y la recomendación que un mánager y un cazador de talentos se ponen en contacto.

Es quizás en función de conocer las reglas de estima y reconocimiento que estas relaciones involucran que uno de los directores entrevistados explica con cierto orgullo que él nunca contactó por su cuenta con ningún headhunter, sino que fueron ellos quienes lo llamaron:

No es por pedantería, pero la verdad es que yo nunca los llamé. Siempre que fui es porque me llamaron. Tengo buena relación porque en algún momento me han llamado, "te quiero conocer", he ido, nos conocimos. (Director, 39 años, casado, 3 hijos)

Distinta es la situación de otro de los gerentes entrevistados, que confiesa que, en un momento de su carrera, cayó en la cuenta de que los headhunters no lo conocían, de que no tenía contacto con ninguno de estos agentes. Consciente de los beneficios laborales que formar parte de esta red conlleva, se puso en contacto con uno de los antiguos gerentes de recursos humanos de su empresa, quién ofició el rol de mediador entre él y la consultora.

En un momento dije, la verdad que a mí los headhunters ni me conocen. Y ahí contacté con uno. En realidad, le pregunté a un ex gerente de Recursos Humanos de acá, que ya no trabaja más. Me dijo: «No te preocupes que yo te ubico». Y me llamaron de ahí. (Gerente, 40 años, casado, 3 hijos)

Del mismo modo, una de las ejecutivas entrevistadas que ingresó en la empresa a través de un headhunter señala que fueron conocidos suyos los que enviaron su currículum a algunos consultores después de que regresara de su estadía de estudios en Londres: «cuando volví de Londres, algunos conocidos míos que tenían contacto con headhunters les llevaron mi currículum». Como ella misma dice, fruto de esta presentación: 
Me reuní con un par de headhunters que conocí a través de contactos. Pensaba que estaba bueno para networking. Me reuní con el número uno de Spencer Stuart y con algún otro. Me parecía importante que tuvieran mis datos, por si sabían de algo. (Gerenta, 36 años, soltera)

Ciertamente, quedar en contacto con un headhunter importante constituye una de las fuentes primordiales de networking, es decir, de construcción de redes de relaciones. Los mánagers entrevistados afirman que, tanto si se quedaran sin empleo como si consideraran cambiar de firma, recurrirían a alguno de los expertos con quienes tuvieron relación. Es esta la fuerza de los lazos débiles (Granovetter, 1973).

El día que yo me canse de trabajar acá, que algún día me va a pasar, llamaré al que mejor me haya caído de los que conocí y diré: «Búscame, ayúdame, recomiéndame, ¿dónde busco?, ¿qué hago?». (Gerente, 33 años, casado, 1 hijo)

Le diré: «Eduardo, estoy disponible. Si tienes algo...». Bueno, Eduardo me tendrá en cuenta y, si surge algo, me llamará o no. Si conoces a un headhunter, se maneja todo en un nivel muy informal. (Director, 55 años, casado, 3 hijos)

En síntesis, los headhunters han logrado situarse como los agentes principales de la circulación y la recolocación de los ejecutivos de alto nivel. Esto es así no solamente por la utilidad del servicio experto que brindan — los «costos de transacción» y los beneficios de su discreción-, sino porque su intermediación devino indispensable en un espacio socioprofesional donde el hecho de que un ejecutivo se presente directamente para un puesto "le hace perder valor».

En general, el ejecutivo de ese nivel se asegura de que su currículum siempre esté actualizado en la base de datos de los hunters. Para un ejecutivo, ir a ofrecerse en una búsqueda le hace perder valor; distinto es si te presenta alguien. Juegan los hunters con este rol de intermediación que es bastante útil. (Director, 41 años, casado, 2 hijos)

\section{Las formas de la transacción, la intervención y la construcción del mercado del management}

La mayoría de los mánagers entrevistados se han reunido, en algún momento de su carrera, con un headhunter que les ha hecho una oferta laboral, aunque en un bajo porcentaje han cambiado de empresa en razón de esa propuesta. Los datos recabados muestran que, si bien un $72,6 \%$ de los entrevistados tuvo contacto con estos agentes, sólo un 9,6\% consiguió su actual puesto por este medio. Como se analiza en Luci (2010a), el cambio de empresa no sucede tan libre y despojadamente como podría creerse desde una concepción que pensara el mercado como un espacio donde la oferta y la demanda rigen libres de otras interposiciones. Por el contrario, el arraigo en una firma no solamente se basa en un tema dinerario - el monto del salario-, sino que cuestiones tan diversas como el apego a la firma, las posibilidades de carrera que se cree tener en 
la empresa, la dificultad de «empezar de cero» en una nueva compañía, entre muchísimos otros factores, intervienen en las decisiones de cambiar de puesto.

Según explica una responsable de recursos humanos de una de las empresas de servicios más globales, en compañías como la suya —una de las firmas de vanguardia mundial en su sector- es más difícil para los headhunters «tentar» a los mánagers para que acepten su oferta y cambien de empresa. Si bien, como ella misma reconoce, su empresa no se caracteriza por pagar los mejores salarios del mercado, la envergadura de la firma a nivel global y el tipo de carrera gerencial que ofrece aseguran la retención de los ejecutivos.

Los hunters saben que a la gente de esta compañía les cuesta más tentarlos, no por el salario, por salario nos pueden tentar perfectamente, sino por el proyecto, por «a qué compañía te mudarías y para qué». Porque, cuando entras a una nueva empresa, entras para después poder ocupar el escalón superior, entonces tiene que ser una compañía que tenga nivel superior y que esa carrera se pueda dar. (Gerenta, 35 años, casada, 1 hijo)

Un gerente de esta misma firma explica que los gerentes de su empresa son el target ideal para los headhunters: puesto que, en la entrevista final con el cliente, los headhunters deben presentar tres o cuatro candidatos, el hecho de que uno de ellos pertenezca a una importante firma como la suya, adiciona calidad a la búsqueda. Como dice Zelizer (1988), los clientes deben ser convencidos acerca del valor y la legitimidad de los productos que van a adquirir. En pos de ello, ofrecer productos socialmente valorados certifica la transacción. Ahora bien, puesto que, como él mismo dice, difícilmente la oferta realizada supere su actual posición en términos de perspectiva profesional, muchos de los mánagers de su empresa comprenden que, en definitiva, son simplemente "parte de una lista» donde el headhunter sabe que la oferta no es superadora. Por eso, según sostiene, últimamente es más cuidadoso e intenta no «exponerse» asistiendo a todas las búsquedas para las cuales lo llaman.

A los headhunters les sirve presentar tres o cuatro candidatos y que uno de ellos sea de esta compañía. Entonces, yo creo que a todos nos ha pasado, en algún momento, de sentirnos parte de una lista, donde era obvio que no nos iban a ofrecer algo mejor que acá. Te ofrecen el mismo trabajo que haces acá y por 15 o 20\% más de sueldo no te vas a ir, entonces casi que te incluyen porque sí. Por ejemplo, una vez me llamaron para el mismo puesto que hago yo en XXX [nombra otra empresa]. Todo bien, yo voy, todos vamos y escuchamos, nadie es tonto, en gran parte trabajamos por el sueldo, entonces está bien ir a escuchar ofertas, pero el tipo de la consultora ya sabe cuánto te van a pagar, ya sabe qué vas a pensar cuando comparas a XXX [su actual empresa] contra XXX [la otra empresa], entonces, te llamó para nada. Por eso estamos teniendo un poco más de cuidado, lo hablamos con varios, en esto de meternos en todas las búsquedas que te llaman, porque ya te das cuenta de que es exponerte, ir a las entrevistas, un manoseo que a veces te desgasta, te genera expectativas. A veces, te desgasta incluso con la misma consultora, porque vas dos o tres veces con los mismos a puestos que no encajan contigo en absoluto. (Gerente, 33 años, casado, 1 hijo) 
En ciertos casos, aunque las ofertas laborales de los headhunters superen en salario la compensación que el mánager recibe en su firma actual (los headhunters conocen el nivel de remuneración del ejecutivo que quieren «cazar» y le ofrecen una suma mayor), la cuestión económica no siempre define el pase de empresa. Un gerente de una de las firmas industriales explica que, pese a haber recibido una buena oferta para ingresar en una importante compañía, optó por permanecer en su empresa. El compromiso que dice tener con una firma que le dio una carrera profesional, y en la cual construyó toda su trayectoria directiva, interviene en el momento de decidir «empezar de nuevo».

- Me llamaron, fui a la entrevista, me ofrecieron un puesto interesante, pero decidí que no.

- ¿Por qué?

- iAh! (Suspira.) No es fácil. Como trabajo y como carrera profesional era interesante, a nivel salario también. Todo eso estaba bien. Pero yo tenía un compromiso bastante fuerte con esta compañía y también acá me habían dado, dentro de todo, una carrera profesional. (Gerente, 42 años, casado, 2 hijos)

En otras ocasiones, la oferta realizada por un headhunter puede servir a un ejecutivo para renegociar mejores condiciones en su firma actual, contraponiendo la propuesta recibida y manifestando la voluntad de abandonar la empresa. Así lo cuenta un gerente de una de las firmas industriales que, tras haber recibido una buena oferta laboral de un headhunter, se decidió a hablar con su superior para exponerle la propuesta que había recibido.

—Una vez estuve a punto de irme. Hablé con mi jefa y, bueno, me retuvieron. - ¿Cómo fue?

- Bueno, ya en un momento, la verdad que había tenido varias llamadas. Y pensé: «Bueno, me voy por esta diferencia de sueldo, si no, no me voy». Cuando fui, me ofreció más de esa diferencia, entonces estuve en un aprieto, porque yo no me quería ir. Estaba muy contento acá. Y bueno, lo planteé en la empresa: «Mira, pasa esto. ¿Qué hago?». Es más, lo hablé con mi jefa. Le dije: «Dame un consejo, porque no sé qué hacer». Y le dije: «Si tu me igualas la oferta, voy a sentir que me estuvieron cagando, porque... ¿Qué? ¿Tengo que venir yo con una propuesta mejor para que ustedes me valoren?». Y..., bueno, me dio su consejo y me retuvo, o sea, me..., me igualó la oferta, sí.

-Y digamos, a igual dinero, sí te interesaba quedarte en esta empresa.

- Sí, después yo le dije que por un poco menos también me quedaba. (Ríe.) Pero, como me dio lo mismo, no se lo discutí. (Ríe.)

(Gerente, 33 años, casado)

Este es otro ejemplo de cómo los headhunters intervienen construyendo el mercado laboral, modificando, como en este caso, la compensación de los ejecutivos, así como la acumulación de prestigio. En efecto, la oferta que el headhunter lanzó a este gerente terminó funcionando como un instrumento para que este renegociara las condiciones del contrato con su empresa: no solamente obtuvo una mejora en su salario, sino que también quedó posicionado 
favorablemente frente a su superior como alguien valorado en el mercado. Sobre todo en un espacio profesional donde la compensación económica no remite solamente a una cuestión dineraria, sino que "estar bien pagado» es, asimismo, una forma de valoración simbólica, la posibilidad de negociar una mejora salarial contribuye, sin duda, a posicionar favorablemente a las personas en la trama de estima intersubjetiva de la empresa (Gautié, Godechot y Sorignet, 2005).

Otro aspecto que señalar es que los headhunters no solamente son agentes activos del mercado del management en función del rol que desempeñan en cuanto a la recolocación ejecutiva, sino que también hacen un papel en la difusión de información que puede intervenir en las conductas de los mánagers. En efecto, si bien generalmente los headhunters representan la parte activa de la relación con ejecutivos, es cierto que los mánagers contactan también con los consultores con quienes tienen mayor confianza. Un gerente de la cadena de supermercados explica la relación de doble vía que tiene con los headhunters con quienes trata. La relación de reciprocidad que entablan quienes logran una cierta confianza permite establecer canales de mutua información.

Yo los llamo y ellos también me llaman. Yo estoy siempre bastante atento al mercado. Por lo general, te llaman para pedirte información. Y también los llamo yo para preguntarles cosas. (Gerente, 36 años, casado, 1 hijo)

La relación que otro de los gerentes entrevistados sostiene con dos consultores manifiesta no solamente la relación que existe entre la acumulación de capital social, la obtención de información y la posibilidad de disponer de mejores recursos para renegociar los términos de la propia carrera, sino además la alta interrelación que existe entre los diversos agentes de la industria del management y cómo estas interacciones contribuyen a construir dicho mercado. Analicemos esto. Por un lado, el puesto que hace unos años ocupó en otra compañía lo dejó en contacto con quien en ese momento era su jefe y hoy es uno de los consultores de una de las empresas de caza de talentos más importante del mundo. Fruto de esta relación, se producen entre ambos intercambios periódicos de información: su amigo headhunter lo llama para pedirle opinión acerca de alguno de los candidatos que considera incluir en una de sus búsquedas y él, por su parte, lo consulta sobre alguna cuestión específica acerca de su carrera laboral (como, por ejemplo, saber si su compensación económica está dentro de los parámetros del mercado). Por otro lado, en su rol de directivo, la relación con un amigo personal que trabaja en una de las principales consultoras globales le sirve para obtener información variada - feedback - en «temas de management» o acerca de cuánto debe pagarle a su equipo. Ya se ha visto que es habitual que los directivos de las empresas verifiquen con consultoras aspectos diversos de la tarea directiva, así como el «estado» del mercado.

De vez en cuando, hablo. Lo que pasa es que hay una relación que excede al hecho de que sea headhunter. El que antes fue gerente general de XXX [su anterior empresa] es headhunter ahora de XXX [una de las principales firmas 
de headhunters del mundo]. Entonces, cada tanto me llama y me pregunta sobre gente, qué opino de este o del otro y yo cada tanto lo llamo: «iMe pagan bien?» o "Pasa esto». Después, tengo otro amigo que trabaja en XXX [una de las principales consultoras del mundo], con él ya no hablo de headhunting, pero sí de cuánto le tengo que pagar a mi equipo, como que ahí también tengo un poco de feedback en temas de management. (Gerente, 34 años, casado)

En uno u otro caso, las conversaciones entabladas pueden contribuir a modificar la acción de alguno de estos agentes, por ejemplo: el headhunter puede valorar en mayor o menor medida a un candidato, así como el mánager puede sentirse alentado a renegociar su salario o a considerar el aumento de la compensación de los miembros de su equipo.

\section{Conclusiones}

El caso particular de estudio que constituyen los cazadores de talentos se inscribe, a la vez que expresa, la creciente importancia del papel que desempeñan los «expertos» de la industria del management en la dinámica interna de las grandes corporaciones (McKenna, 2007). Buena parte de las funciones organizacionales — como el caso de la búsqueda ejecutiva que aquí se analiza- queda, por cierto, en sus manos.

Efectivamente, los headhunters han logrado instituirse en agentes centrales de la circulación y la recolocación de los ejecutivos de alto nivel: la valoración de su expertise y las exigencias de discreción que esta cuestión requiere los posicionan como los expertos por excelencia del mercado de compraventa de fuerza de trabajo directiva. Con base en la construcción de redes de referencia y recomendación, estos intermediarios ofician de puente entre una persona y un puesto de trabajo, y contribuyen, además, a construir el mercado de oferta y demanda de mánagers. En este sentido, fue posible comprobar dos cuestiones: por un lado, los headhunters construyen relaciones socioprofesionales de estima y reconocimiento que, a la vez que fundan juicios de valor sobre las personas, intervienen en la posibilidad de obtener un mejor puesto. Por otro lado, tanto a través de las ofertas de puestos que producen, como de la difusión de información que alimenta decisiones y conductas de los mánagers, se evidencian como agentes activos de la constitución del mercado de trabajo directivo.

\section{Referencias bibliográficas}

AZPIAZU, Daniel y BASUALDO, Eduardo (2009). Transformaciones estructurales de la economía argentina: Una aproximación a partir del panel de grandes empresas 19912005. Buenos Aires: PNUD.

Bessy, Christian (1997). "Cabinets de recrutement et formes d'intermédiation sur le marché du travail». En: Bessy, Christian y Eymard-Duvernay, François (eds.). Les intermédiaires du marché du travail. París: PUF.

BuRT, Ronald (1995). «Le capital social, les trous structuraux et l'entrepreneur». Revue Française de Sociologie, 36 (4), 599-628. 
Callon, Michel (1998). "The embeddedness of economic markets in economics». En: Callon, Michel (ed.). The Laws of the Markets. Oxford: Blackwell Publishers.

DefIllipPI, Robert J. y ARTHUR, Michael B. (1994). "The boundaryless career: a competency-based perspective». Journal of Organizational Behaviour, 15 (4), 307-324.

Eymard-Duvernay, François y MARCHAL, Emmanuelle (1997). Façons de recruter. Paris: Métailié.

Eymard-Duvernay, François y MARCHAL, Emmanuelle (2000). "Qui calcule trop finit par déraisonner: Les experts du marché du travail». Sociologie du Travail, 42, 411-432.

FINLAY, William y COVERDILl, James E. (2000). «Risk, opportunism, and structural holes: How headhunters manage clients and earn fees». Work and Occupations, 27 (3), 377-405.

Fligstein, Neil y Dauter, Luke (2007). «The Sociology of Markets». Annual Review of Sociology, 33, 105-128.

Gautié, Jérôme; Godechot, Olivier y Sorignet, Pierre-Emmanuel (2005). "Arrangement institutionnel et fonctionnement du marché du travail: Le cas de la chasse de tête». Sociologie du Travail, 47, 383-404.

Goffman, Erving (1951). «Symbols of Class Status». British Journal of Sociology, 2 (4), 294-304.

GranOveTter, Mark (1973). «The Strenght of Weak Ties». American Journal of Sociology, 78 (6), 1360-1380.

LUCI, Florencia (2009). «Aprender a liderar: los MBA y el reclutamiento de las Escuelas de Negocios en Buenos Aires: Notas etnográficas sobre el mundo del management». Revista de Antropología Social, 18, 317-338.

- (2010a). L'intégration réussie à l'élite managériale: la constitution des dirigeants de grandes entreprises en Argentine. Tesis de doctorado. París: EHESS, 548 p.

- (2010b). "La división sexual del trabajo de mando: Carreras femeninas en las grandes firmas argentinas». Revista Katálysis, 13, 29-39.

MCKENNA, Christopher (2007). The world's newest profession: Management consulting in the twentieth century. Cambridge: Cambridge University Press.

NefFA, Julio C. y Korinfeld, Silvia (2006). «Los intermediarios del mercado de trabajo: Situación en un momento de crisis». Revista de Trabajo, 2, 77-104.

SElim, Monique (1999). «Ethnicisation de l'entreprise et culturalisation du marché». Journal des Anthropologues, 77-78, 19-33.

Simmel, Georg (1908). Sociologia: Estudios sobre las formas de socialización. Alianza: Madrid, 1986.

WRIGHT, Susan (1994). Anthropology of Organizations. Routledge: London.

ZELIZER, Viviana (1988). «Beyond the polemics on the market: Establishing a theoretical and empirical agenda». Sociological Forum, 3 (4), 614-634. 